Review

\title{
Are physicians willing to ration health care? Conflicting findings in a systematic review of survey research ${ }^{\text {is }}$
}

\author{
Daniel Strech $^{\mathrm{a}, \mathrm{b}, *}$, Govind Persad ${ }^{\mathrm{b}}$, Georg Marckmann $^{\mathrm{c}}$, Marion Danis ${ }^{\mathrm{b}}$ \\ a Institute for History, Ethics and Philosophy of Medicine, Centre of Public Health and Healthcare, \\ Hannover Medical School, Carl-Neuberg Str. 1, 30625 Hannover, Germany \\ b Department of Bioethics, National Institutes of Health, Bethesda, MD, USA \\ c Institute for Ethics and History of Medicine, University of Tübingen, Germany
}

\section{A R T I C L E I N F O}

\section{Keywords:}

Healthcare rationing

Bedside rationing

Physicians' attitudes

Systematic review

Survey research

Bioethics

\begin{abstract}
A B S T R A C T
Background: Several quantitative surveys have been conducted internationally to gather empirical information about physicians' general attitudes towards health care rationing. Are physicians ready to accept and implement rationing, or are they rather reluctant? Do they prefer implicit bedside rationing that allows the physician-patient relationship broad leeway in individual decisions? Or do physicians prefer strategies that apply explicit criteria and rules?

Objectives: To analyse the range of survey findings on rationing. To discuss differences in response patterns. To provide recommendations for the enhancement of transparency and systematic conduct in reviewing survey literature.

Methods: A systematic search was performed for all English and non-English language references using CINAHL, EMBASE, and MEDLINE. Three blinded experts independently evaluated title and abstract of each reference. Survey items were extracted that match with: (i) willingness to ration health care or (ii) preferences for different rationing strategies. Results: 16 studies were eventually included in the systematic review. Percentages of respondents willing to accept rationing ranged from $94 \%$ to $9 \%$.

Conclusions: The conflicting findings among studies illustrate important ambivalence in physicians that has several implications for health policy. Moreover, this review highlights the importance to interpret survey findings in context of the results of all previous relevant studies.
\end{abstract}

(c) 2008 Elsevier Ireland Ltd. All rights reserved.

\section{Contents}

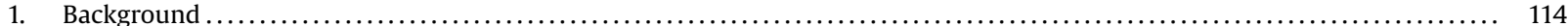

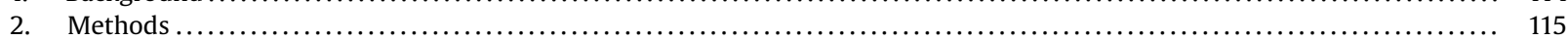

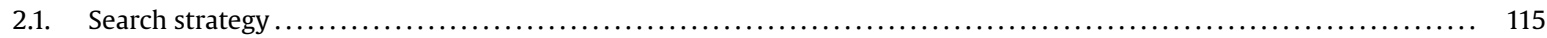

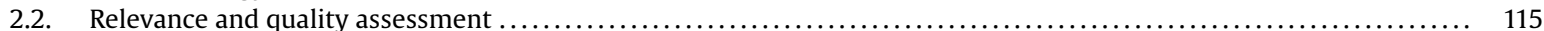

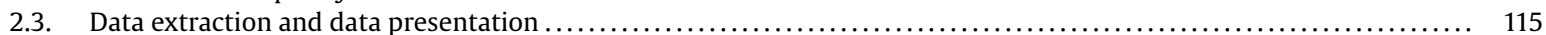

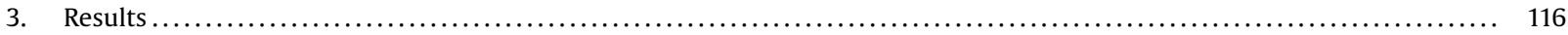

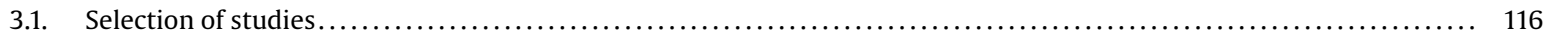

\footnotetext{
is The views expressed by the authors do not necessarily reflect policies of the NIH or the US Department of Health and Human Services.

* Corresponding author at: Institut für Geschichte, Ethik und Philosophie der Medizin, Carl-Neuberg Str. 1, 30625 Hannover, Germany.

Tel.: +49511532 2709; fax: +495115325650.

E-mail address: strech.daniel@mh-hannover.de (D. Strech).
} 


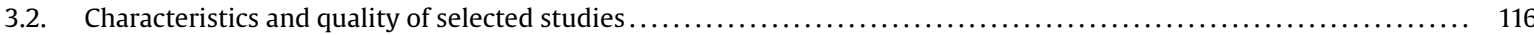

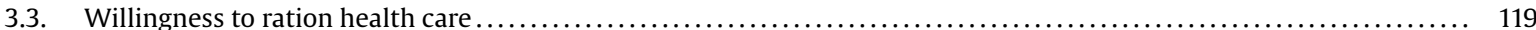

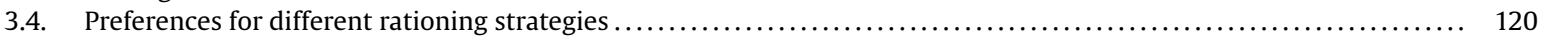

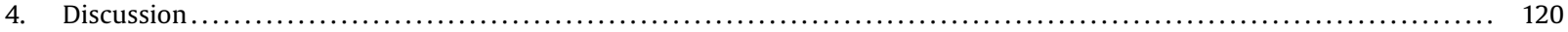

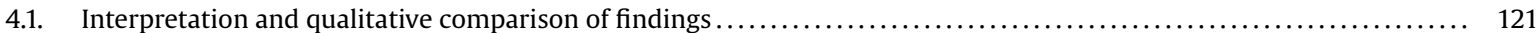

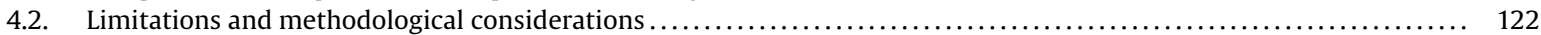

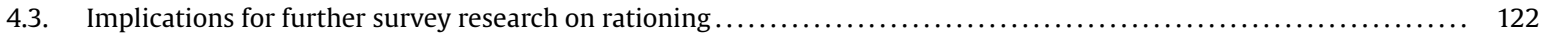

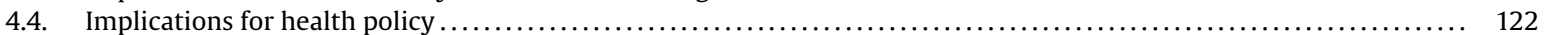

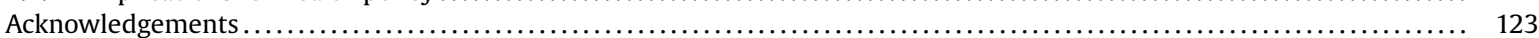

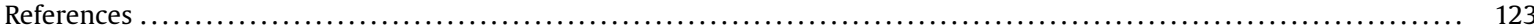

\section{Background}

Health care rationing, here understood as withholding beneficial interventions for cost reasons, occur at all levels in all health care systems around the world. Countries with very different health care systems and levels of health care spending all grapple with the challenge of reconciling a steadily increasing demand for health care services with limited or even declining financial resources. If health care rationing is inevitable, it must be done fairly and efficiently. Several approaches to ethically acceptable rationing have been developed, many of which especially demand that allocation decisions at both macro- and micro-levels be transparent, explicit and consistent [1,2]. While these normative requirements are largely undisputed in academic discourse, they have not yet been implemented widely in everyday medical practice. However, some recent publications provide an analysis about how physicians might handle bedside rationing [3].

To ensure that physicians are willing to participate in and support the implementation of instruments for rationing, we need valid empirical information about physicians' attitudes regarding both rationing in general and different approaches of rationing in particular. The success of health policy efforts to influence medical practice and achieve transparent, efficient and just cost-containment highly depends on physicians' attitudes and behaviour. Accordingly, a broad spectrum of qualitative and quantitative research has been conducted internationally to gather empirical information about physicians' general attitude towards rationing. Are physicians ready to accept and implement rationing, or are they reluctant? Other interview and survey research has examined physicians' preferences for certain strategies of rationing. Do they prefer bedside rationing that does not refer to explicit criteria, but instead allows the physician-patient relationship broad leeway in individual decisions and permits varying decisions among patients? Or do physicians prefer strategies that apply explicit criteria found in higher level cost-conscious guidelines [4]?

Empirical studies on rationing yield extremely variable and multi-faceted results. Rationing can involve a wide spectrum of resources ranging from the most to the least cost and time intensive and from the most to the least fungible. Explicit or rule-based strategies employ well defined criteria, such as severity of disease, effectiveness, or cost-effectiveness that health policy makers can acknowledge when making coverage decisions for medical interventions or when developing cost-conscious clinical guidelines. Typically (albeit not necessarily), such explicit rationing decisions are made at the macro- or meso-level of the health care system rather than in the individual physician-patient relationship (micro-level). In contrast, implicit rationing strategies rely on individual clinical decisions in the physician-patient interaction. These implicit strategies do not follow explicit and transparent criteria or rules. Rather, they are the - often inevitable result of budgetary restrictions or (financial) incentives. These cost-containment instruments, therefore, are often called implicit rationing strategies themselves in contrast to explicit strategies like cost-conscious guidelines or regulated benefit catalogues.

A variety of different study methodologies, different backgrounds and perspectives on the same ethical dilemma, and related practical problems further increase the complexity. Different studies also provide conflicting evidence and thus allow health policy makers to choose those findings that best fit their particular beliefs or interests. To reduce the probability of one-sided and potentially biased interpretations of empirical findings, more systematic reviews that acknowledge these differences in a methodologically systematic way should be conducted on specific questions in this field of research. Systematic reviews are necessary and helpful for responsible and explicit decision making in health policy [5,6]. The need for systematization and transparency is especially pressing due to the complexity, variability and inconsistency of both qualitative and quantitative research on different topics of health policy, health care management, and health care ethics. A systematic review of qualitative research on health care rationing already proved that research findings in this area are heterogeneous [7]. In this paper, we present a systematic review of quantitative survey research with physicians on the topic of rationing.

In developing a sound approach for reviewing the socio-empirical evidence on rationing, we face various methodological and practical challenges, as systematic reviews on socio-empirical research in other fields have shown $[8,9]$. Current methods for systematic reviews (e.g. most of the Cochrane Reviews) tend to favour quantitative evidence from clinical trials, and focus on rather narrow research questions such as the effects of medical interventions on specific outcomes. These types of systematic reviews are necessary and helpful for many clinical and health policy questions. Most issues in health policy and bioethics, however, require a systematic synthesis of evidence across a range of different research questions and are sometimes related to more fuzzy concepts 
like "rationing". For example, as we show in this paper, the heterogeneity of item wording in different surveys focussing on similar research topics such as rationing needs a special method of data analysis and synthesis. While several systematic reviews of qualitative interview research (such as focus groups or in-depth interviews) have been conducted, there are few systematic reviews of quantitative survey research [10]. As such, given the need for sound methods for summarizing research in health policy, this paper is intended to contribute by accurately representing and analyzing the range of quantitative survey findings.

\section{Methods}

\subsection{Search strategy}

We performed a systematic literature search using CINAHL(1982-December 2007), EMBASE (1988-December 2007), and MEDLINE (1966-December 2007). No time or language restrictions were applied. The keyword catalogue and indexing of articles differ considerably from database to database. This was of special importance in our case because the search algorithms had to reflect a broad review question including three core search terms: (1) quantitative survey research, (2) physicians as participants, and (3) rationing as primary issue. Using the indexing tools from the OVID platform, we adapted the search algorithms to the specific keyword catalogue of each database. ${ }^{1}$ We also employed index terms from articles initially identified as relevant. As in every systematic review, our search algorithm had to weigh sensitivity against specificity. Accordingly, we developed the search algorithm with a cluster model that proved to be effective in a review of qualitative evidence [7]. In this model, database specific keywords were grouped together by the Boolean operator "or," while the three corresponding clusters were connected with the operator "and". The three clusters consist of keywords corresponding to (A) participants, (B) issues of rationing, and (C) paradigm, study design. The final search algorithms for each database, as well as interim results of retrieved references, are presented in Table 1 . We supplemented this search by hand-searching relevant key journals and searching the bibliographies of key references. For a critical discussion and further information about methodologies for systematic reviews of socio-empirical research and empirical bioethics see [11].

\subsection{Relevance and quality assessment}

To assess the relevance of the references identified by our search strategy three experts in the subject of the systematic review (DS, GP, GM) independently evaluated the title and abstract of each reference (DS and GP evaluated MEDLINE references, DS and GM evaluated EMBASE and CINAHL references). The references were blinded for source, author, and year of publication. To be included in the

\footnotetext{
1 See www.ovid.com.
}

final analysis studies had to meet the following criteria: (1) provide quantitative data through telephone surveys, mailsurveys, or internal distribution-surveys; (2) be conducted in a developed or high-income country; (3) include practicing physicians (GPs and specialists) as participants and (4) provide data for physicians' attitudes concerning (i) willingness or agreement to ration health care, (ii) implicit or explicit rationing strategies, or (iii) prioritisation criteria. ${ }^{2}$ The two experts scored the relevance of each reference with respect to the explicit inclusion criteria, using the following classification: (1) irrelevant, (2) slightly irrelevant, (3) somewhat relevant and (4) relevant. References with unclear relevance because abstracts were absent or did not provide sufficient information were read as full text. Experts' scores were compared to assess agreement. All references rated somewhat relevant or relevant were then read full text to assess final relevance. In cases of discrepancy, the fourth expert (MD) was consulted to determine the final relevance value for each reference. The inter-rater reliability was calculated by Cronbach's alpha [12], using the SPSS package (v. 14.0).

Although no gold standard or commonly accepted checklist for the quality assessment of survey research exist, we determined that the following criteria are important across surveys to appraise internal validity and generalizability (external validity): (1) country, (2) year of conduct, (3) sample base and method of sampling, (4) sample size calculation, (5) sample size, (6) validation of questionnaire, (7) survey method, and (8) response rate (see Table 2).

\subsection{Data extraction and data presentation}

To frame the analysis, we extracted items that match with one of the following issues: (i) willingness to ration health care or (ii) preferences for different rationing strategies. Items that match one of these issues were grouped together in a table indicating the original reference, the original wording, and the revealed agreement or disagreement in percentages (see Tables 3-5). Willingness to accept rationing was conceptualized as agreement with statements that accept or justify rationing in some way, or as disagreement with statements that argue against rationing in some way.

The included references present findings with quite different question wordings which is partly a result of the conceptual fuzziness of the term "rationing". This methodological variability requires a critical interpretation and qualitative comparison of survey findings in the context of all available data. This systematic review can provide further and also more valid information than a single survey does. In order to allow a coherent qualitative comparison of survey findings, the presentation of frequency data was harmonized. When dichotomous frequency data were given for statements that argue against rationing, the percentage of physicians rejecting the statement, and thus accepting rationing, were presented: e.g. if according to a

\footnotetext{
${ }^{2}$ Findings for attitudes of prioritization criteria will be published elsewhere.
} 
Table 1

Search algorithms. Numbers in parentheses reflect the number of retrieved references.

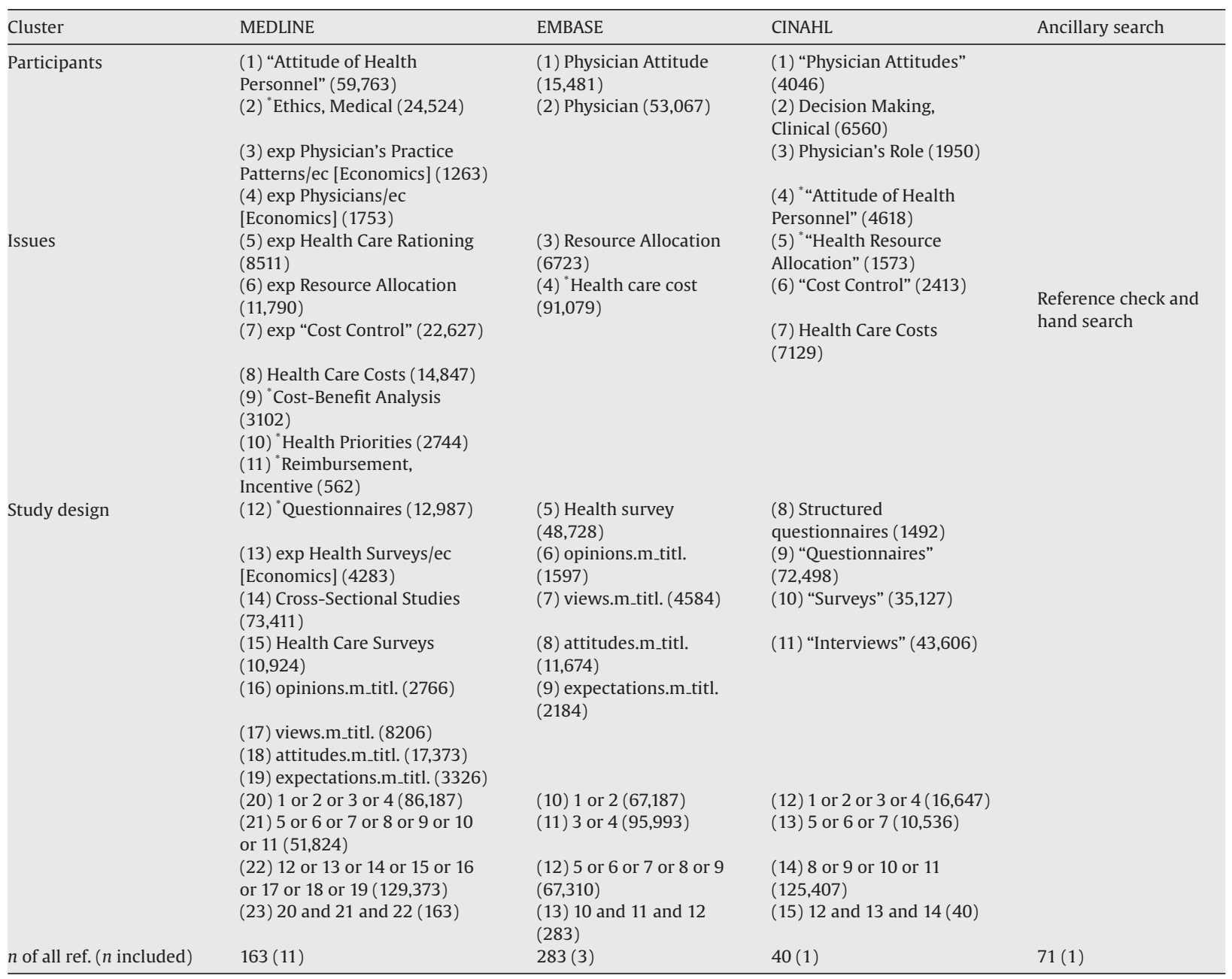

survey item $35 \%$ of physicians were resistant to rationing, we presented these findings as $65 \%$ of physicians being willing to ration health care $(100-35 \%=65 \%)$. For nondichotomous response variables, we pooled data to achieve dichotomous data: e.g. if $7 \%$ strongly agreed, $23 \%$ agreed, $34 \%$ disagreed, and $36 \%$ strongly disagreed with health care rationing we presented these findings as $30 \%$ of physicians being willing to ration health care $(7 \%+23 \%=30 \%)$. Frequencies for neutral items were represented as $50 \%$ positive and $50 \%$ negative responses: e.g. if $7 \%$ strongly agreed, $23 \%$ agreed, $10 \%$ neither agreed nor disagreed, 34\% disagreed, and $26 \%$ strongly disagreed with health care rationing, we presented these findings as $35 \%$ of physicians being willing to ration health care $(7 \%+23 \%+[10 \% / 2]=35 \%)$. We excluded items that employed response scales that disproportionately emphasized agreement or disagreement: e.g. $7 \%$ strongly agreed, $23 \%$ agreed, $50 \%$ only little agreement, and $20 \%$ not at all. This criterion excluded some items from Arnesen and Fredriksen [13] and excluded the studies from Tabenkin et al. [14] and Forsberg et al. [15].

\section{Results}

\subsection{Selection of studies}

The systematic literature search yielded 557 references, of which 15 were eventually included in the systematic review after relevance assessment (see Table 1) [13,16-29]. Cronbach's alpha was 0.91 .

\subsection{Characteristics and quality of selected studies}

The 15 studies were conducted in 8 different countries (Canada, Italy, The Netherlands, Norway, Sweden, Switzerland, the United Kingdom, and the United States of America). Altogether, the studies included 10,921 participants. The average sample size was 727 with an average response rate of $60 \%$. The studies were heterogeneous in their research methodology: 12 studies used mail-survey (total $n=8797$ participants) with up to 3 mailings, 3 used telephone or face-to-face interviews with closed questions (total $n=2124$ participants). 5 studies used a full sample 
Table 2

Study characteristics, n.s. = not specified.

\begin{tabular}{|c|c|c|c|c|c|c|c|}
\hline Reference & Country & Year of conduct & Sample base and sampling & $\begin{array}{l}\text { Sample size } \\
\text { (sample size } \\
\text { calculation) }\end{array}$ & $\begin{array}{l}\text { Validation of } \\
\text { questionnaire }\end{array}$ & Survey method: & Response rate \\
\hline Allan and Innes [17] & $\begin{array}{l}\text { Canada, British } \\
\text { Columbia }\end{array}$ & n.s. & $\begin{array}{l}\text { Random sample of British Columbia } \\
\text { Medical Association's (BCMA) } \\
\text { membership database }\end{array}$ & $600(-)$ & $\begin{array}{l}\text { Pilot-tested for } \\
\text { clarification }\end{array}$ & $\begin{array}{l}3 \text { mailings } \\
\text { (Dillman total } \\
\text { design method) }\end{array}$ & $47 \%$ \\
\hline Arnesen and Fredriksen [13] & Norway & 1993 & $\begin{array}{l}\text { All general practitioners in the } \\
\text { northernmost counties in Norway }\end{array}$ & $151(-)$ & n.s. & $\begin{array}{l}1 \text { mailing, } 1 \\
\text { reminder }\end{array}$ & $72 \%$ \\
\hline Baines et al. [16] & United Kingdom & 1996 & $\begin{array}{l}\text { All senior partners of each of the } 105 \\
\text { general practices in one English health } \\
\text { authority (Lincolnshire) }\end{array}$ & $105(-)$ & $\begin{array}{l}\text { Pilot-tested for } \\
\text { feasibility }\end{array}$ & 1 mailing & $67 \%$ \\
\hline Bernat et al. [21] & United States & 1995 & $\begin{array}{l}\text { Random sample of the American } \\
\text { Academy of Neurology (AAN) member } \\
\text { database }\end{array}$ & $547(+)$ & $\begin{array}{l}\text { Pilot-tested for } \\
\text { clarification }\end{array}$ & 3 mailings & $75 \%$ \\
\hline Blendon et al. [22] & United States & 1994 & $\begin{array}{l}\text { Random sample of the American } \\
\text { Medical Association's (AMA) Masterfile } \\
\text { of Physicians }\end{array}$ & $495(-)$ & n.s. & $\begin{array}{l}\text { Advance letter. } \\
\text { Telephone calls to } \\
\text { conduct the survey } \\
\text { or to schedule an } \\
\text { appointment. } 800 \\
\text { number was } \\
\text { provided to allow } \\
\text { to call in and } \\
\text { complete the } \\
\text { interview. }\end{array}$ & $55 \%$ \\
\hline Bovier et al. [23] & Switzerland & 1998 & $\begin{array}{l}\text { All practicing physicians from the } \\
\text { membership files of the Geneva } \\
\text { Medical Association and the Swiss } \\
\text { Association of Interns/Registrars, } \\
\text { Geneva Section }\end{array}$ & $1184(-)$ & $\begin{array}{l}\text { Use of validated scales } \\
\text { (data for internal } \\
\text { consistency was given). } \\
\text { Standardized } \\
\text { translation procedure }\end{array}$ & $\begin{array}{l}1 \text { mailing, } 2 \\
\text { reminders }\end{array}$ & $59 \%$ \\
\hline van Delden et al. [20] & Netherlands & n.s. & $\begin{array}{l}\text { Systematic selection of oncologists, } \\
\text { cardiologists, and nursing home } \\
\text { physicians in the southwest region of } \\
\text { the Netherlands who responded to a } \\
\text { not specified first contact. }\end{array}$ & $80(-)$ & $\begin{array}{l}\text { Content of } \\
\text { questionnaire based on } \\
\text { a literature study. } \\
\text { Further validation n.s. }\end{array}$ & $\begin{array}{l}\text { Face-to-face } \\
\text { interviews }\end{array}$ & $60 \%$ \\
\hline Edwards et al. [24] & $\begin{array}{l}\text { United Kingdom } \\
\text { (Wales) }\end{array}$ & n.s. & $\begin{array}{l}\text { Random sample of GPs and consultants } \\
\text { across Wales }\end{array}$ & $1250(-)$ & $\begin{array}{l}\text { Content of } \\
\text { questionnaire } \\
\text { generated through a } \\
\text { literature search and } \\
\text { through discussions } \\
\text { with physicians. } \\
\text { Pilot-tested }\end{array}$ & 1 mailing & $57 \%$ \\
\hline Holloway et al. [25] & United States & 1999 & $\begin{array}{l}\text { Random sample of the American } \\
\text { Academy of Neurology (AAN) member } \\
\text { database }\end{array}$ & $800(+)$ & $\begin{array}{l}\text { Draft survey was } \\
\text { reviewed and revised } \\
\text { by task force. } \\
\text { Pilot-tested for } \\
\text { clarification. }\end{array}$ & $\begin{array}{l}3 \text { mail- } \\
\text { ings + incentive }\end{array}$ & $44 \%$ \\
\hline
\end{tabular}


Table 2 (Continued)

\begin{tabular}{|c|c|c|c|c|c|c|c|}
\hline Reference & Country & Year of conduct & Sample base and sampling & $\begin{array}{l}\text { Sample size } \\
\text { (sample size } \\
\text { calculation) }\end{array}$ & $\begin{array}{l}\text { Validation of } \\
\text { questionnaire }\end{array}$ & Survey method: & Response rate \\
\hline Hurst et al. [18] & $\begin{array}{l}\text { Italy, Norway, } \\
\text { Switzerland, } \\
\text { United Kingdom }\end{array}$ & 2003-2004 & $\begin{array}{l}\text { Random sample of GPs identified } \\
\text { through official list of the Norwegian } \\
\text { Medical Association, the Swiss Medical } \\
\text { Association, published listings of UK } \\
\text { GPs, and regional listings of Italian } \\
\text { general practitioners and members of } \\
\text { the Italian Society of Internal Medicine. } \\
400 \text { individuals were drawn in each } \\
\text { country }\end{array}$ & $1600(-)$ & $\begin{array}{l}\text { Content of } \\
\text { questionnaire } \\
\text { generated through a } \\
\text { literature search and by } \\
\text { referring to prior } \\
\text { qualitative research. } \\
\text { New Items rated for } \\
\text { content validity. } \\
\text { Pilot-tested with } \\
\text { cognitive } \\
\text { questionnaires. Scales } \\
\text { were tested for internal } \\
\text { consistency. }\end{array}$ & $\begin{array}{l}2 \text { mail- } \\
\text { ings + incentive }\end{array}$ & $43 \%$ \\
\hline Reichert et al. [19] & United States & 1998 & $\begin{array}{l}\text { All internal medicine house staff (145) } \\
\text { and attending physicians ( } 44 \text { ) in the } \\
\text { Division of Internal Medicine at the } \\
\text { Mount Sinai-New York University } \\
\text { Medical Center }\end{array}$ & $189(-)$ & n.s. & 2 mailings & $71 \%$ \\
\hline Rosen and Karlberg [26] & Sweden & n.s. & $\begin{array}{l}\text { Random sample equally split into } \\
\text { heads of departments and general } \\
\text { practitioners selected from relevant } \\
\text { registries }\end{array}$ & $300(-)$ & Pilot-tested & $\begin{array}{l}2 \text { mailings } \\
\text { (Dillman total } \\
\text { design method) }\end{array}$ & $60 \%$ \\
\hline Shrank et al. [27] & United States & 2003 & $\begin{array}{l}\text { Random sample of physician members } \\
\text { of the California Medical Association } \\
\text { (CMA) }\end{array}$ & $1200(+)$ & $\begin{array}{l}\text { Questionnaire } \\
\text { constructed through a } \\
\text { collaborative process } \\
\text { and piloted for } \\
\text { validation. }\end{array}$ & $\begin{array}{l}3 \text { mail- } \\
\text { ings + incentive }\end{array}$ & $50 \%$ \\
\hline Sulmasy et al. [28] & United States & 1997 & $\begin{array}{l}\text { Resurvey of a subsample of the Young } \\
\text { Physicians Survey (YPS) of } 1991 \text {. } \\
\text { Eligible physicians had completed } \\
\text { residency training and practiced in one } \\
\text { of the } 75 \text { largest metropolitan service } \\
\text { areas }\end{array}$ & $1549(-)$ & $\begin{array}{l}\text { Pilot-tested and } \\
\text { field-tested for length, } \\
\text { clarity, comprehension, } \\
\text { and validity using the } \\
\text { techniques of cognitive } \\
\text { pretesting. }\end{array}$ & $\begin{array}{l}\text { Telephone } \\
\text { interviews by } \\
\text { trained } \\
\text { professional } \\
\text { interviewers. }\end{array}$ & $74 \%$ \\
\hline Whynes and Baines [29] & United Kingdom & 2000 & $\begin{array}{l}\text { All senior partners of each of the } \\
\text { general practices in Trent (east-central } \\
\text { England) }\end{array}$ & $862(-)$ & n.s. & 1 mailing & $61 \%$ \\
\hline
\end{tabular}


Table 3

Willingness to ration health care among physicians.

\begin{tabular}{|c|c|c|c|}
\hline \# & Item & Agree & Disagree \\
\hline 1.1 & $\begin{array}{l}\text { Patients should be made aware that not all health care needs can be met } \\
\text { (Whynes) }\end{array}$ & $94 \%$ & \\
\hline 1.2 & Trying to contain costs is the responsibility of every physician (Bovier) & $93 \%$ & \\
\hline 1.3 & $\begin{array}{l}\text { The cost of a test or medication is only important if the patient has to pay for it } \\
\text { out-of-pocket (Bovier) }\end{array}$ & & $92 \%$ \\
\hline 1.4 & Cost is an important consideration when making medication choices (Reichert) & $88 \%$ & \\
\hline 1.5 & $\begin{array}{l}\text { Good quality prescribing takes into account the value for money of the } \\
\text { medicines prescribed and not just their appropriateness, effectiveness and } \\
\text { safety of treatment for the patient (Baines) }\end{array}$ & $79 \%$ & \\
\hline 1.6 & $\begin{array}{l}\text { Every individual has a right to have his or her health-care needs met, even if } \\
\text { troubles are trivial (Rosen) }\end{array}$ & & $77 \%$ \\
\hline 1.7 & $\begin{array}{l}\text { I am willing to sacrifice some degree of efficacy in order to make drugs more } \\
\text { affordable for my patients (Reichert) }\end{array}$ & $71 \%$ & \\
\hline 1.8 & Better knowledge of costs would change my ordering of therapies (Allan) & $70 \%$ & \\
\hline 1.9 & $\begin{array}{l}\text { It is a GP's duty to take the cost-effectiveness of treatment into account when } \\
\text { recommending a treatment or referring a patient to hospital (Baines) }\end{array}$ & $69 \%$ & \\
\hline 1.10 & $\begin{array}{l}\text { In daily consultations with your patients, do you feel like an administrator of } \\
\text { society's health funds? (Arnesen) }\end{array}$ & $69 \%$ & \\
\hline 1.11 & $\begin{array}{l}\text { I would advocate using riluzole in my patients with ALS, irrespective of the } \\
\text { costs or indirect effect on patients of other physicians, if there were even a } \\
\text { marginal benefit to my patients of doing so (Holloway) }\end{array}$ & & $67 \%$ \\
\hline 1.12 & $\begin{array}{l}\text { Public health services should always offer the best possible care, irrespective of } \\
\text { cost (Rosen) }\end{array}$ & & $64 \%$ \\
\hline 1.13 & Cost influences my decisions when ordering investigations (Allan) & $62 \%$ & \\
\hline 1.14 & It is important to discuss total costs with patients (Shrank) & $62 \%$ & \\
\hline 1.15 & $\begin{array}{l}\text { A neurologist's professional responsibility is to consider only the medical } \\
\text { interests of his/her patient without the concern about the final impact of } \\
\text { treatment decisions on other patients (Holloway) }\end{array}$ & & $60 \%$ \\
\hline 1.16 & Better knowledge of costs would change my ordering of investigations (Allan) & $59 \%$ & \\
\hline 1.17 & Costs influence my decisions when ordering therapies (Allan) & $56 \%$ & \\
\hline 1.18 & $\begin{array}{l}\text { GPs should not have to consider expenditure when prescribing drugs to their } \\
\text { patients and prescribing budgets should therefore be abolished (Whynes) }\end{array}$ & & $56 \%$ \\
\hline 1.19 & $\begin{array}{l}\text { Cost to society is important in my decisions to use or not to use an intervention } \\
\text { (Hurst) }\end{array}$ & $51 \%$ & \\
\hline 1.20 & $\begin{array}{l}\text { Everybody has to make sacrifices and suffer the consequences of less costly } \\
\text { health care (Bernat) }\end{array}$ & $50 \%$ & \\
\hline 1.21 & $\begin{array}{l}\text { In an era of scarce resources for health care, it is ethical for health insurance } \\
\text { companies to make trade-offs of health benefits between groups of enrollees } \\
\text { (an example of such a trade-off is some patients with epilepsy developing side } \\
\text { effects from a less costly medication so more people can receive preventive } \\
\text { services) (Bernat) }\end{array}$ & $47 \%$ & \\
\hline 1.22 & $\begin{array}{l}\text { Budgets should not be introduced into general practice, as it is not the job of } \\
\text { GPs to ration health care (Baines) }\end{array}$ & & $41 \%$ \\
\hline 1.23 & $\begin{array}{l}\text { If a GP thinks that a health promotion clinic is not effective (but will have no } \\
\text { harmful effect on patients), the practice can still run the clinic if the } \\
\text { government pays it for so doing (Baines) }\end{array}$ & & $39 \%$ \\
\hline 1.24 & $\begin{array}{l}\text { It is the government's duty to provide the finance necessary to meet all the } \\
\text { health needs of the population (Baines) }\end{array}$ & & $38 \%$ \\
\hline 1.25 & $\begin{array}{l}\text { I should sometimes deny beneficial but costly services to certain patients } \\
\text { because resources should go to other patients that need them more (Hurst) }\end{array}$ & $37 \%$ & \\
\hline 1.26 & $\begin{array}{l}\text { Physicians need to adopt more cost saving measures even if such measures } \\
\text { sometimes reduce quality of care (Bernat) }\end{array}$ & $28 \%$ & \\
\hline 1.27 & $\begin{array}{l}\text { A good doctor's prime concern is for the interests of patients, who are } \\
\text { committed to his or her care, even if this leads to a less efficient allocation of } \\
\text { the scarce resources (van Delden) }\end{array}$ & & $9 \%$ \\
\hline
\end{tabular}

of a defined physician population, 8 studies used a random sample of a defined physician population, and 2 studies did not adequately report if they used a full or random sample of physicians. Sample size calculation was only reported in 3 out of 15 studies. The procedures for validation of the questionnaire were also described in rather heterogeneous ways and in 4 studies were not specified at all. Validation strategies ranged from unspecified pilot-testing for clarification and feasibility to techniques for cognitive pretesting and reporting of data for consistency and factor analysis.

\subsection{Willingness to ration health care}

In identifying items related to rationing we encountered the conceptual problem that there is no universally accepted definition for rationing. Many studies avoid the term "rationing" and rather ask whether physicians are willing to consider cost or cost-effectiveness in individual patient care decisions or to take responsibility for scarce health care funds. Considering costs does not necessarily involve rationing in the sense that physicians withhold a net-benefit from their patients, as there are other ways to 
Table 4

Preferences for explicit strategies of rationing.

\begin{tabular}{|c|c|c|}
\hline \# & Item & Agree \\
\hline 2.1 & $\begin{array}{l}\text { If rationing decisions in a healthcare system must be made, these decisions should be informed by results of well } \\
\text { conducted cost-effectiveness studies (Holloway) }\end{array}$ & $93 \%$ \\
\hline 2.2 & Would you support more explicit prioritisation of NHS waiting lists? (Answers by GPs) (Edwards) & $87 \%$ \\
\hline 2.3 & $\begin{array}{l}\text { You are concerned about the possibility that some or all of [...] [several] episodes [in a patient with epilepsy] may be } \\
\text { pseudoseizures and propose admission to the hospital for 24-h EEG monitoring with closed circuit television. } \\
\text { However, the request for authorization for admission is refused by the patient's health insurance plan. You make an } \\
\text { appeal by telephone but are told that the plan never authorizes such EEG monitoring for a possible diagnosis of } \\
\text { pseudoseizures: To prevent situations like the one described, the federal government should authorize panels of } \\
\text { physicians and researchers to set uniform, minimum standards specifying which diagnostic tests (and their } \\
\text { indications) must be covered by every health insurance plan (Bernat) }\end{array}$ & $71 \%$ \\
\hline 2.4 & $\begin{array}{l}\text { If rationing decisions in a healthcare system must be made, they should be made away from the bedside, not while } \\
\text { practitioners are caring for patients (Holloway) }\end{array}$ & $70 \%$ \\
\hline 2.5 & $\begin{array}{l}\text { Physicians should adhere to clinical guidelines that discourage the use of interventions that have a small proven } \\
\text { advantage over standard interventions but cost much more (Hurst) }\end{array}$ & $69 \%$ \\
\hline 2.6 & Waiting lists are the fairest way to ration health care (Whynes) & $62 \%$ \\
\hline 2.7 & Would you support more explicit prioritisation of NHS waiting lists? (Answers by consultants) (Edwards) & $57 \%$ \\
\hline 2.8 & $\begin{array}{l}\text { Physician support for a cost-containment approach: Requiring physicians to use practice guidelines in their clinical } \\
\text { decision making (Blendon) }\end{array}$ & $56 \%$ \\
\hline 2.9 & $\begin{array}{l}\text { Clinical guidelines that discourage the use of diagnostic or therapeutic interventions that have a small, proven } \\
\text { advantage over standard interventions but cost much more should, in general, be adhered to by physicians (Sulmasy) }\end{array}$ & $55 \%$ \\
\hline 2.10 & $\begin{array}{l}\text { Managed care networks should have the authority to deny payment for diagnostic tests on the basis of nationally } \\
\text { accepted critical pathways or clinical practice guidelines (publicly available) (Bernat) }\end{array}$ & $53 \%$ \\
\hline 2.11 & $\begin{array}{l}\text { Physician support for a cost-containment approach: Not covering certain expensive medical treatments like } \\
\text { transplants and hip replacements (Blendon) }\end{array}$ & $35 \%$ \\
\hline 2.12 & $\begin{array}{l}\text { Clinical guidelines that discourage the use of diagnostic or therapeutic interventions that have a small, proven } \\
\text { advantage over standard interventions but cost much more should, in general, be enforced by health care payers } \\
\text { (Sulmasy) }\end{array}$ & $23 \%$ \\
\hline 2.13 & $\begin{array}{l}\text { Managed care networks should have the authority to deny payment for diagnostic tests on the basis of critical } \\
\text { pathways or clinical practice guidelines drafted solely by the managed care networks (proprietary and not publicly } \\
\text { available) (Bernat) }\end{array}$ & $7 \%$ \\
\hline
\end{tabular}

contain cost like choosing the cheapest option from several equally effective treatments. In practice, however, there is a high probability that physicians who take into account the cost impact of their decisions will withhold options that provide little benefit at high cost-which would qualify as rationing. Due to this conceptual and empirical overlap, we included items that referred to cost-containment in general and rationing more specifically to receive a picture as complete as possible of physicians' attitudes towards rationing. In 12 studies, physicians were asked about their willingness to accept rationing with a total of 27 items that highlighted this issue. There was substantial heterogeneity in the extent of willingness to rationing among studies. The percentage of respondents who were willing to accept rationing ranged from $94 \%$ to $9 \%$ with an unweighted mean of $60.3 \%$ and standard deviation of $20.5 \%$ (Table 3 ).

\subsection{Preferences for different rationing strategies}

In 7 studies, physicians were asked questions that reveal physicians' attitudes to different rationing strategies. We identified a total of 16 items that highlighted this issue. 13 items focused on explicit strategies of rationing (Table 4), and 3 items focused on implicit strategies of rationing (Table 5). The extent of agreement with explicit and implicit rationing strategies was also quite variable. The acceptance of explicit strategies ranged from $93 \%$ to $7 \%$ with an unweighted mean of $60.7 \%$ and standard deviation of $21.2 \%$. The agreement with implicit strategies ranged from $66 \%$ to $21 \%$ with an unweighted mean of $39.7 \%$ and standard deviation of $23.5 \%$.
Table 5

Preferences for implicit strategies of rationing.

\begin{tabular}{llc}
\hline$\#$ & Item & Agree \\
\hline 3.1 & $\begin{array}{l}\text { GPs should receive incentive payments } \\
\text { to motivate them to improve their } \\
\text { prescribing (Whynes) }\end{array}$ & $32 \%$ \\
& $\begin{array}{l}\text { Physician support for a } \\
\text { cost-containment approach: Placing } \\
\text { government limits on fees that can be } \\
\text { charged by individual physicians and } \\
\text { hospitals (Blendon) }\end{array}$ & \\
& $\begin{array}{l}\text { Personal financial incentives designed } \\
\text { to encourage physicians to be more } \\
\text { restrained in their use of medical } \\
\text { resources for individual patients are } \\
\text { ethically acceptable (Sulmasy) }\end{array}$ & \\
&
\end{tabular}

\section{Discussion}

At first sight, an average score (mean) of $60.6 \%$ of general willingness to ration health care among physicians could indicate that there is substantial willingness to consider cost and efficiency data in addition to effectiveness data and patient preferences, when making medical decisions. The average score of $60.7 \%$ and $39.7 \%$ for acceptance of more specific strategies of rationing indicate that willingness to ration health care decreases when rationing is seen in practice. However, due to the heterogeneous phrasing of items, the different participants of the surveys (GPs and consultants), and the high standard deviations, interpreting and comparing the survey findings in greater detail is of special importance as a mandatory element of the 
developing methodology of systematic reviews we present here. We have therefore divided the discussion of our findings into four sections: (i) interpretation and qualitative comparison of findings, (ii) limitations and methodological considerations, (iii) implications for further survey research on rationing, and (iv) implications for health policy.

\subsection{Interpretation and qualitative comparison of findings}

Differences in item wording can explain at least some of the high variability of agreement across questions that explored physicians' attitudes towards rationing (Table 3). First, items that revealed high willingness to accept rationing (e.g. \#1.1-1.5, which range from 94\% to $79 \%$ ) employ rather general and noncommittal descriptions of rationing. For instance, physicians were asked whether "trying to contain cost" (\#1.2) is the responsibility of physicians, or whether costs should be "taken into account" when prescribing (\#1.5) a treatment. Other items used tendentious phrasing such as "... is only important if ..." (\#1.3), “... not just ..." (\#1.5), or “... even if troubles are trivial" (\#1.6). Most of these rather general items do not explain the specific reasons why and how costs should be considered or contained.

Second, items that applied more comfortable or vague words for rationing such as "cost-consideration" (e.g. \#1.2, \#1.4, \#1.5) rather than uncomfortable or specific words like "rationing" or "denying" of medical services (\#1.22, \#1.25) revealed higher willingness (93\%, $88 \%$, and $79 \%$ vs. $41 \%$ and $37 \%$.

Third, willingness to accept rationing noticeably decreases if the aims and consequences of costconsideration come into play. Items that explicitly mention that drugs having "smaller incidence of side effects" (\#1.21) or "beneficial" services (\#1.25) will be restricted and therefore sometimes "reduce quality of care" (\#1.26) revealed lower willingness to ration (47\%, 37\%, 28\%).

Fourth, we can distinguish between questions regarding rationing on society's behalf and concerns for the patient's financial burden and ability to pay. Whereas the latter represented by item \#1.3 yields very high agreement (92\%) other items that explicitly asked for rationing on society's behalf (\#1.11, \#1.20, \#1.26) yield lower agreement (69\%, $51 \%, 37 \%)$.

Fifth, we see that items that elicited lower willingness to accept rationing often did not mention the opportunity costs such as the impact on other patients or on society as a whole. For instance, there was only $39 \%$ disagreement with item \#1.23: "If a GP thinks that a health promotion clinic is not effective (but will have no harmful effect on patients), the practice can still run the clinic if the government pays it for so doing" and 38\% disagreement with item \#1.24: "It is the government's duty to provide the finance necessary to meet all the health needs of the population". One could imagine greater disagreement with both statements if they included an additional sentence like “... even if this leads to negative impact on other patients or on society as a whole."

Altogether, physicians apparently are quite willing to consider costs in clinical decisions. However, they seem to be reluctant to engage in rationing if this involves withholding beneficial treatment from their patients. With regard to the scarcity of health care resources physicians acknowledge that they no longer can ignore the cost impact of their decisions, but they would prefer measures that increase efficiency rather then withhold beneficial care (i.e. ration). This is certainly not very surprising as these cost-containment strategies do not involve conflict with the physicians' traditional ethical commitment to the best interest of the individual patient.

Differences in response patterns for items that asked more specifically whether rationing decisions should be made implicitly or explicitly (Tables 4 and 5) have similar explanation. Items that used rather general and noncommittal language found higher preferences for rationing with explicit criteria. For example, one item that found 93\% agreement asked if unavoidable rationing decisions should "be informed by results of well conducted cost-effectiveness studies" (\#2.1). Accordingly, items (\#2.2 or \#2.4) that explored preferences for explicit rationing without any specification revealed high percentages of agreement ( $87 \%$ and $71 \%$ ). Agreement with explicit rationing decreases as soon as rationing measures and possible consequences are specified. For instance, wording like "guidelines that discourage the use of ..." (\#2.9, \#2.12) or "managed care networks should have the authority to deny ..." (\#2.10,\#2.13) results in lower agreement with explicit rationing (from 55\% to 7\%). Findings among surveys also show the different variables that can influence the degree of agreement with the different statements. For instance, surveys found differences between general practitioners (GPs) and consultants (\#2.2 and \#2.7) with higher agreement among GPs (87\%) in comparison to consultants (57\%). Surveys found differences in response patterns correlating with the following variables: (i) if clinical guidelines should be "adhered to by physicians" vs. "enforced by health care payers" (\#2.9 vs. \#2.12) and (ii) if practice guidelines are "nationally accepted" vs. "drafted solely by the managed care networks" (\#2.10 vs. \#2.13). Items with similar phrasing also showed moderate differences in response patterns, for example \#2.5 and \#2.9 employed quite similar phrasing but revealed $69 \%$ and $55 \%$ of agreement.

Only three items directly ask for attitudes to implicit strategies (\#3.1, \#3.2, and \#3.3). Here again, one item that uses rather noncommittal language by describing the aim of incentive payments to motivate physicians "to improve their prescribing" (\#3.1) reveals higher agreement than another item that describes the aim as encouraging physicians "to be more restrained" (\#3.3).

Another point requires further caution in interpreting the results. Many answers to these questions about explicit or implicit rationing are contaminated with the underlying acceptance of rationing in general. Therefore, they do not reflect "pure" preferences concerning the choice between explicit vs. implicit rationing strategies. The answers to item \#2.11 are certainly influenced by the two examples transplants and hip replacements that both can provide significant benefit for the patient. Not surprisingly, there is low agreement with an explicit approach to withhold these treatments, which probably results more from a disagreement with rationing of transplants and hip replacement 
than a negative attitude towards an explicit vs. implicit allocation of these interventions.

\subsection{Limitations and methodological considerations}

Traditional methods for systematically reviewing research findings (e.g. most of the Cochrane Reviews [30]) are limited in several ways regarding their application to survey research and other methods applied in health policy and bioethics. For example, traditional systematic reviews usually deal with issues and study designs that correspond well to the controlled vocabulary of electronic databases like MEDLINE, EMBASE and others. Choosing search terms for randomized controlled trials, specific diseases, and specific study endpoints, therefore, does not pose a big challenge. In contrast, for systematic reviews of survey research that deal with specific ethical issues, finding adequate search terms that are represented by the databases' controlled vocabulary is much more difficult. Search algorithms for systematic reviews of survey research therefore have to be adapted to the databases' vocabulary to enhance sensitivity and specificity of literature searches. Further methodological considerations concerning reviewing literature are discussed more detailed in [11].

When initiating this review, we first aimed to pool data assessed by similar survey items. This proved infeasible due to considerable differences in question wording, and we chose to present survey findings qualitatively (Tables 3-5). Nevertheless, grouping different survey items together requires subjective judgments about sufficient similarity between different headings such as "willingness to engage in rationing" or "preferences for different strategies of rationing". We acknowledged this source of bias by illustrating the original wording in the tables, thus allowing readers to judge whether they agree with our grouping or not.

Can the specific history and current situation of the different national health care systems explain the heterogeneity of physicians' responses? This is an important question that would involve statistical analysis of possible predictors such as the time when the study was conducted, the political context, and the structure of the health care system. Unfortunately, the small number of studies to date does not allow this analysis.

This systematic review in the field of health care rationing focused on physicians as participants and on survey research instruments as method. However, the specific questions quantitative survey research asks will not cover the whole phenomenon of rationing. Other research methodologies such as qualitative research can add useful information [7]. Furthermore, other stakeholders like patients, other health care professionals like nurses, and the general public have participated in survey research, and systematic reviews of their views and attitudes about rationing will provide further valuable information for health policy.

\subsection{Implications for further survey research on rationing}

As shown in the sections above agreement with explicit or implicit rationing decreases considerably as soon as rationing approaches and possible consequences are specified. To receive valid information about physicians' willingness to accept rationing it is important to choose a precise wording that avoids the conceptual ambiguity of rather general terms like "cost-containment" or "costconsideration". Given the fact that there is no universally accepted definition of rationing, it might be preferable to avoid the term "rationing" completely and rather ask more precisely what kind of services are withhold from patients for cost reasons. For the potential of biased answers through the negative connotation of the word rationing see also [31]. Less ambiguous wording can be found within our review for example in item \#1.25 asking about denying "beneficial but costly services" or even more precise in item \#2.12 concerning interventions that have a "small proven advantage over standard interventions but cost much more". Unfortunately, no survey directly compared preferences for implicit vs. explicit rationing strategies that address an open research question. In addition, most items concerning explicit and implicit rationing are contaminated with the underlying acceptance of rationing. Future studies therefore should try to separate these two different questions, for example by asking whether physicians would prefer explicit, rule-based rationing over implicit, casebased rationing assuming that rationing is inevitable and access to some beneficial treatments has to be restricted by one or the other way. This might reveal more valid attitudes towards different forms of rationing and give important clues what role physicians prefer in setting limits to health care services.

For health care policy, management, and ethics, knowing more about the individual factors that influence the willingness of rationing in general and the acceptance of specific tools such as cost-conscious guidelines is important. Little research has been conducted that investigates the spectrum of these factors, as well as the relative importance of these factors in different contexts.

\subsection{Implications for health policy}

The conflicting findings in the summarized survey literature illustrate important ambivalence in physicians. A majority seems willing to set limits on the health care services available to their patients. On the other hand, physicians' willingness decreases considerably if they are asked more specifically about rationing health care (e.g. certain types of guidelines) or enforcement of rationing by health authorities. One possible explanation could be that physicians dislike explicit methods of rationing, preferring implicit strategies that allow rationing decisions informed by the individual judgments of physicians. But as shown in Table 4, physicians also have heterogeneous preferences about explicit and implicit strategies of rationing. Another and perhaps more plausible interpretation may be that physicians agree that they should consider costs in making treatment decisions for their patients but they are rather reluctant to engage in bedside rationing which involves withholding beneficial treatment from their patients for cost reasons. For further discussion about the ethical dilemmas of bedside rationing see $[3,32]$. 
Effective implementation of explicit tools for rationing (e.g. practice guidelines that in future might also consider costs more explicitly) therefore faces considerable barriers. Before explicit methods of rationing can be implemented, physicians have to be convinced of the usefulness and the ethical necessity of such methods. Several steps should be acknowledged in this process. Qualitative studies with physicians have shown that there is little attention so far to general concerns of justice, the application of consistent processes, and explicitness when dealing with scarce resources [33]. Implementation of explicit tools of rationing will only be effective if physicians are aware of the clinical and societal relevance of these ethical topics.

The development, implementation, and evaluation of explicit tools for rationing must also acknowledge physicians' concerns. In order to facilitate rationing, respect for individual variations and avenues for the review of decisions are two elementary requirements that help address physicians' worries about standardization and guidelines in clinical practice [3]. More specifically, tools like costconscious guidelines should not rely on cost-effectiveness data in isolation [4]. As we have learned from Oregon's initial priority list a pure cost-effectiveness approach can lead to counterintuitive rankings [34]. When setting thresholds for cost-effectiveness, several ethical constraints such as severity of disease or lack of alternative treatment need careful consideration [35].

Finally, individual approaches to explicit rationing in different institutional contexts should be monitored for appropriateness, opportunities, and limitations [2]. As the studies analyzed in our review show, willingness to accept rationing and acceptance of particular strategies of rationing currently is rather low as these strategies are increasingly developed and enforced by health authorities. To avoid this roadblock, transparency about every step of the process of systematic data synthesis or guideline development should be provided to maximize the confidence of the end-users of the information such as physicians, patients, and health care managers. Current and future empirical and conceptual health services research might detect new aspects of rationing decisions, such as implicit value judgments, that should be made public together with information about data sources, statistical methods, inclusion of unpublished data from industry, conflict of interest, and others [36].

As well as having implications for the development and implementation of tools for sound and responsible rationing, the findings of our review also support some new recommendations for the critical appraisal of survey findings. Due to the wide variability in response patterns resulting from different factors built in the item wording that cannot be specified and verified with high validity, we recommend that, if possible, survey findings should always be interpreted and critically appraised in the context of other studies with similar research focus. This recommendation parallels similar recommendations where critical appraisal of clinical trials is concerned. The CONSORT statement, for instance, highlights the importance of discussing trial findings in the context of existing evidence [37]. This discussion should be as systematic as possible, and not limited to studies that support the results of the newest survey.
Ideally, as shown in our study, we recommend a systematic review of existing survey findings prior to the conduct or interpretation of a new survey.

Due to the increasing quantity and relevance of socioempirical data in health technology assessment, the application of systematic reviews in the fields of health policy, health care management, and health care ethics has become more and more important. Our systematic review not only presents a method of synthesizing the available quantitative empirical evidence on these issues, but also provides new information that might help health policy decision makers, physicians and ethicists to understand the determinants and complexity of physicians' attitudes towards rationing, and thus might help to improve implementation of fair and efficient strategies for rationing. However, the approach we have chosen should not be considered as definitive. Further experiences with methodological variations and different issues could be helpful to further improve the interplay between socio-empirical data on the one hand and health care decision making and theory building on the other hand.

\section{Acknowledgements}

Funding: Supported in part by grant 01GP0608 from the German Federal Ministry of Education and Research and a grant for Daniel Strech from the German Academic Exchange Service.

\section{References}

[1] Emanuel EJ. Justice and managed care. Four principles for the just allocation of health care resources. The Hastings Centre Report 2000;30:8-16.

[2] Daniels N, Sabin JE. Setting limits fairly. Oxford: Oxford University Press; 2002.

[3] Hurst SA, Danis M. A framework for rationing by clinical judgment. Kennedy Institute of Ethics Journal 2007;17:247-66.

[4] Eccles M, Mason J. How to develop cost-conscious guidelines. Health Technology Assessment 2001;5:1-69.

[5] McCullough LB, Coverdale JH, Chervenak FA. Constructing a systematic review for argument-based clinical ethics literature: the example of concealed medications. Journal of Medicine and Philosophy 2007;32:65-76.

[6] Bravata DM, McDonald KM, Shojania KG, Sundaram V, Owens DK. Challenges in systematic reviews: synthesis of topics related to the delivery, organization, and financing of health care. Annals of Internal Medicine 2005;142:1056-65.

[7] Strech D, Synofzik M, Marckmann G. How physicians allocate scarce resources at the bedside. A systematic review of qualitative studies. Journal of Medicine and Philosophy 2008;33:80-99.

[8] Popay J, Rogers A, Williams G. Rationale and standards for the systematic review of qualitative literature in health services research. Qualitative Health Research 1998;8:341-51.

[9] Mills E, Jadad AR, Ross C, Wilson K. Systematic review of qualitative studies exploring parental beliefs and attitudes toward childhood vaccination identifies common barriers to vaccination. Journal of Clinical Epidemiology 2005;58:1081-8.

[10] Mills EJ, Nachega JB, Bangsberg DR, Singh S, Rachlis B, Wu P, et al. Adherence to HAART: a systematic review of developed and developing nation patient-reported barriers and facilitators. PLoS Medicine 2006;3:e438.

[11] Strech D, Synofzik M, Marckmann G. Systematic reviews of empirical bioethics. Conceptual challenges and practical recommendations. Journal of Medical Ethics 2008;34:472-7.

[12] Landis JR, Koch GG. The measurement of observer agreement for categorical data. Biometrics 1977;33:159-74.

[13] Arnesen T, Fredriksen S. Coping with obligations towards patient and society: an empirical study of attitudes and practice among Norwegian physicians. Journal of Medical Ethics 1995;21:158-61. 
[14] Tabenkin H, Gross R, Greenberg SB, Steinmetz D, Elhayany A. Primary care physicians in Israel: self-perception of their role in the healthcare system and policy makers' and patients' perception of them as gatekeepers. The Israel Medical Association Journal 2001;3:893-7.

[15] Forsberg E, Axelsson R, Arnetz B. Performance-based reimbursement in health care. Consequences for physicians' cost awareness and work environment. European Journal of Public Health 2002;12:44-50.

[16] Baines DL, Tolley KH, Whynes DK. The ethics of resource allocation: the views of general practitioners in Lincolnshire, UK. Social Science \& Medicine 1998;47:1555-64.

[17] Allan GM, Innes GD. Do family physicians know the costs of medical care? Survey in British Columbia. Canadian Family Physician 2004;50:263-70.

[18] Hurst SA, Slowther AM, Forde R, Pegoraro R, Reiter-Theil S, Perrier A, et al. Prevalence and determinants of physician bedside rationing: data from Europe. Journal of General Internal Medicine 2006;21:1138-43.

[19] Reichert S, Simon T, Halm EA. Physicians' attitudes about prescribing and knowledge of the costs of common medications. Archives of Internal Medicine 2000;160:2799-803.

[20] van Delden JJ, Vrakking AM, van der Heide A, van der Maas PJ. Medical decision making in scarcity situations. Journal of Medical Ethics 2004;30:207-11.

[21] Bernat JL, Ringel SP, Vickrey BG, Keran C. Attitudes of US neurologists concerning the ethical dimensions of managed care. Neurology 1997;49:4-13.

[22] Blendon RJ, Kohut A, Benson JM, Donelan K, Bowman C. Health system reform. Physicians' views on the critical choices. JAMA 1994;272:1546-50.

[23] Bovier PA, Martin DP, Perneger TV. Cost-consciousness among Swiss doctors: a cross-sectional survey. BMC Health Services Research 2005;5:72.

[24] Edwards RT, Boland A, Wilkinson C, Cohen D, Williams J. Clinical and lay preferences for the explicit prioritisation of elective waiting lists: survey evidence from Wales. Health Policy (Amsterdam Netherlands) 2003;63:229-37.

[25] Holloway RG, Ringel SP, Bernat JL, Keran CM, Lawyer BL. US neurologists: attitudes on rationing. Neurology 2000;55:1492-7.
[26] Rosen P, Karlberg I. Opinions of Swedish citizens, health-care politicians, administrators and doctors on rationing and health-care financing. Health Expectations 2002;5:148-55.

[27] Shrank WH, Joseph GJ, Choudhry NK, Young HN, Ettner SL, Glassman $\mathrm{P}$, et al. Physicians' perceptions of relevant prescription drug costs: do costs to the individual patient or to the population matter most? The American Journal of Managed Care 2006;12:545-51.

[28] Sulmasy DP, Bloche MG, Mitchell JM, Hadley J. Physicians' ethical beliefs about cost-control arrangements. Archives of Internal Medicine 2000;160:649-57 [see comment].

[29] Whynes DK, Baines DL. Primary care physicians' attitudes to health care reform in England. Health Policy (Amsterdam, Netherlands) 2002;60:111-32.

[30] Higgins JPT, Green S, editors. Cochrane handbook for systematic reviews of interventions 4.2.5 [updated May 2005]. In: The Cochrane Library, Issue 3. Chichester, UK: John Wiley \& Sons, Ltd., 2005.

[31] Ward NS, Teno JM, Curtis JR, Rubenfeld GD, Levy MM. Perceptions of cost constraints, resource limitations, and rationing in United States intensive care units: results of a national survey. Critical Care Medicine 2008;36:471-6.

[32] Pearson SD. Caring and cost: the challenge for physician advocacy. Annals of Internal Medicine 2000;133:148-53.

[33] Hurst SA, Hull SC, DuVal G, Danis M. Physicians' responses to resource constraints. Archives of Internal Medicine 2005;165:639-44.

[34] Ubel PA, Loewenstein G, Scanlon D, Kamlet M. Individual utilities are inconsistent with rationing choices: a partial explanation of why Oregon's cost-effectiveness list failed. Medical Decision Making 1996;16:108-16 [see comments].

[35] Nord E, Pinto JL, Richardson J, Menzel P, Ubel P. Incorporating societal concerns for fairness in numerical valuations of health programmes. Health Economics 1999;8:25-39.

[36] Strech D, Tilburt JC. Value judgments in the analysis and synthesis of evidence. Journal of Clinical Epidemiology 2008;61:521-4.

[37] Altman DG, Schulz KF, Moher D, Egger M, Davidoff F, Elbourne D. The revised CONSORT statement for reporting randomized trials: explanation and elaboration. The CONSORT Group. Annals of Internal Medicine 2001;134:663-94. 